\title{
Renal Dysfunction, Metabolic Syndrome and Cardiovascular Disease Mortality
}

\author{
David Martins, Chizobam Ani, Deyu Pan, Omolola Ogunyemi, and Keith Norris \\ Department of Medicine, Charles Drew University of Medicine and Science, 1731 E 20th Street, Los Angeles, CA 90059, USA \\ Correspondence should be addressed to David Martins, dsomartins@yahoo.com
}

Received 26 August 2009; Accepted 21 January 2010

Academic Editor: Maria Luz Fernandez

Copyright () 2010 David Martins et al. This is an open access article distributed under the Creative Commons Attribution License, which permits unrestricted use, distribution, and reproduction in any medium, provided the original work is properly cited.

Background. Renal disease is commonly described as a complication of metabolic syndrome (MetS) but some recent studies suggest that Chronic Kidney disease (CKD) may actually antecede MetS. Few studies have explored the predictive utility of co-clustering CKD with MetS for cardiovascular disease (CVD) mortality. Methods. Data from a nationally representative sample of United States adults (NHANES) was utilized. A sample of 13115 non-pregnant individuals aged $\geq 35$ years, with available follow-up mortality assessment was selected. Multivariable Cox Proportional hazard regression analysis techniques explored the relationship between co-clustered CKD, MetS and CVD mortality. Bayesian analysis techniques tested the predictive accuracy for CVD Mortality of two models using co-clustered MetS and CKD and MetS alone. Results. Co-clustering early and late CKD respectively resulted in statistically significant higher hazard for CVD mortality $(\mathrm{HR}=1.80, \mathrm{CI}=1.45-2.23$, and $\mathrm{HR}=3.23, \mathrm{CI}=2.56-3.70)$ when compared with individuals with no MetS and no CKD. A model with early CKD and MetS has a higher predictive accuracy $(72.0 \%$ versus $67.6 \%)$, area under the ROC ( 0.74 versus 0.66$)$, and Cohen's kappa ( 0.38 versus 0.21$)$ than that with MetS alone. Conclusion. The study findings suggest that the co-clustering of early CKD with MetS increases the accuracy of risk prediction for CVD mortality.

\section{Introduction}

Cardiovascular disease (CVD) remains the leading cause of death and disability in the United States, accounting for approximately 1 of every 2.8 deaths recorded in the United States [1]. The tendency for the major CVD risk factors to occur in clusters informed considerable research interest leading to the description of Metabolic Syndrome (MetS) [2]. The National Cholesterol Education Program (NCEP) Adult Treatment Panel (ATP) III accepts the cooccurrence of abdominal obesity, atherogenic dyslipidemia, elevated blood pressure, insulin resistance with or without glucose intolerance, prothrombotic states, and proinflammatory states as MetS [3]. Although the precise pathophysiological mechanism of MetS is unknown, there is ample evidence of the association of this syndrome with CVD and CKD.

CKD is the ninth leading cause of death in the United States with an estimated 19 million U.S. adults (6\%) reported to have some form of CKD [4]. The association of several components of MetS with CKD [5-8] has engendered the perception of CKD as a long-term complication of MetS. However, the establishment of hyperinsulinemia and glucose intolerance as the pathophysiological bases for insulin resistance in patients with renal disease along with the recent implication of the renin-angiotensin system in local pancreatic islet structure and function suggests a plausible common pathophysiological mechanism for MetS and CKD $[9,10]$.

CKD is an established independent predictor of CVD mortality and a long-term complication of several of the individual components of MetS. However, the value of the diagnosis of MetS as an independent predictor of CVD mortality is controversial $[2,11]$. A recent review of existing prospective data concludes that the CVD risk associated with the diagnosis of MetS varies with the components employed in the diagnosis of the syndrome and that the diagnosis of MetS itself only modestly predicts (Relative Risk 1.651.93) CVD mortality $[12,13]$. Many of the components of MetS are also established CVD risk factors and the clinical challenge has always been the establishment of 
the additional risk posed by the diagnosis of MetS above and beyond the sum of the CVD risk factors employed in its diagnosis.

We hypothesize that the inclusion of indices of CKD in the diagnostic criteria for MetS will refine its identity as a clinical entity and improve its predictive value for CVD mortality. The purpose of our study is to explore the effect of including indices of CKD as defined by the National Kidney Foundation Kidney Disease Outcomes Quality Initiative (KDQI) study [14] in the diagnostic criteria for MetS on the predictive value of the syndrome for CVD mortality in a nationally representative sample.

\section{Subjects and Methods}

This study utilized data from a nationally representative sample of the civilian, noninstitutionalized US population collected by the Centers for Disease Control and Prevention during the third National Health and Nutrition Examination Surveys (NHANES III) conducted at 89 survey locations between January 1, 1988, and December 31, 1994. This survey utilized a complex multistage cluster design and oversampled persons 60 years and older, non-Hispanic black individuals, and Mexican American individuals to enhance the precision of prevalence estimates in these groups. Inperson interviews were conducted in sampled households, and all subjects were invited to participate in medical examinations conducted at a nearby NHANES III mobile examination center. Interviews consisted of demographic, socioeconomic, dietary, as well as health-related questions, and the mobile examination component consisted of medical and dental examinations, physiological measurements, and laboratory tests. The prevalence of common chronic conditions and associated risk factors was also determined during this survey. Details of the survey design and examination procedures have been previously published $[15,16]$. The primary study outcome, CVD mortality was recorded from the NHANES III mortality follow-up data. This mortality follow-up data relied on a probabilistic match between NHANES III and National Death Index (National Center for Health Statistics (NCHS) 2006) death certificate records available for a total of 18,149 participants of the total 30,818 (59\%) adult participants (those 17 years and older) that completed the initial interviews and physical examination and laboratory assessment at a mobile examination center [17]. Mortality assessments were conducted from the baseline interview in 1988-1994 through the end of the follow-up period in December 31, 2000. These mortality data included cause specific mortality and mortality dates. Cause specific mortality was coded using the International Classification of Diseases Ninth Revision (ICD-9) Clinical Modification for deaths occurring between 1988 and 1998 and the International Classification of Diseases Tenth Revision for deaths occurring between 1999 and 2000. We selected the total sample of individuals with mortality assessment during the follow-up period $(n=18,149)$. Of these we excluded participants who were pregnant and less than 35 years of age to get a total sample size of 13115 for analysis.

\section{Study Variables}

3.1. Outcome Variable. CVD mortality was the primary outcome variable of interest. Using the NHANESIII ICD-9 codes for deaths occurring between 1988 and 1998 and the ICD-10 Tenth Revision for deaths occurring between 1999 and 2000 we created a dichotomous variable with categories for CVD mortality and no-CVD mortality [17].

3.2. Primary Predictor Variable. The primary predictor variable was cocustered MetS and CKD. To compute this variable we first defined the individual metabolic risk factors or conditions consistent with the National Cholesterol Education Program (NCEP) Adult Treatment Panel III (ATP III) classification among the sample [18]: specifically (a) Elevated waist circumference: $M e n \geq 40$ inches $(102 \mathrm{~cm})$ and Women, $\geq 35$ inches $(88 \mathrm{~cm}$ ), (b) Elevated triglycerides: $\geq 150 \mathrm{mg} / \mathrm{dL}$, (c) Reduced HDL cholesterol: Men $\leq 40 \mathrm{mg} / \mathrm{dL}$ or Women $\leq 50 \mathrm{mg} / \mathrm{dL}$, (d) Elevated blood pressure: $\geq 130 / 85 \mathrm{~mm} \mathrm{Hg}$, (e) Elevated fasting glucose: $\geq 110 \mathrm{mg} / \mathrm{dL}$, (f) Prothrombotic state: fibrinogen $>350 \mathrm{mg} / \mathrm{dL}$, and (g) Proinflammatory state: C-reactive proteins: $>0.5 \mathrm{mg} / \mathrm{dL}$. Then we identified study participants meeting a minimum of three of these criteria and classified them as having MetS. We also created a trichotomous $\mathrm{CKD}$ variable using the KDQI study classification for stages of CKD [19]. Individuals in stages 35 (eGFR of $0-59 \mathrm{~mL} / \mathrm{min} / 1.73 \mathrm{~m}^{2}$ ) were classified as having late CKD; individuals in the stages 1 and 2 (eGFR of $60-$ $89 \mathrm{~mL} / \mathrm{min} / 1.73 \mathrm{~m}^{2}$ or eGFR of $>90 \mathrm{~mL} / \mathrm{min} / 1.73 \mathrm{~m}^{2}$ with proteinuria) were classified as having early CKD. All other individuals were classified as having normal kidney function. Finally we created a dummy variable with six categories for all the possible permutations of renal dysfunction and MetS from the two variables described earlier. The categories were as follows: (a) No MetS and No CKD, (b) No MetS and Early CKD, (c) No MetS and Late CKD, (d) MetS and No CKD, (e) MetS and Early CKD, and (f) MetS and Late CKD.

3.3. Covariates. Covariates included factors demonstrated to be associated with CVD mortality and include sociodemographic, smoking status, history of CVD, and mortality follow-up duration. Specifically, demographic factors included gender, age was categorized as $<65$ years and $\geq 65$ years of age, gender, race, ethnicity, and poverty/income ratio. Smoking status was categorized as never smoked, former smokers and current smokers. Individuals with a selfreported history of physician diagnosis of stroke, myocardial infarction, and congestive heart failure were categorized as having a history of CVD. The time from baseline assessment, mortality assessment or death was included in the analysis to control for any temporal influences of time on the outcome of interest (CVD mortality).

\section{Statistical Analysis}

Descriptive analyses of all the variables utilized in the data analysis were conducted. We explored the distribution of the variables among categories of CVD and no CVD mortality. 
TABLE 1: Sample weighted distribution of study variables $(n=13115)$.

\begin{tabular}{|c|c|}
\hline Variables & $\%$ \\
\hline \multicolumn{2}{|l|}{ Race } \\
\hline White & $49.9 \%$ \\
\hline African american & $24.8 \%$ \\
\hline Hispanic \& other & $25.4 \%$ \\
\hline \multicolumn{2}{|l|}{ Gender } \\
\hline Male & $46.7 \%$ \\
\hline Female & $53.3 \%$ \\
\hline \multicolumn{2}{|l|}{ Age (years) } \\
\hline$<65$ & $60.0 \%$ \\
\hline$\geq 65$ & $40.0 \%$ \\
\hline \multicolumn{2}{|l|}{ Poverty/income ratio } \\
\hline$<1$ & $36.3 \%$ \\
\hline$\geq 1$ & $63.7 \%$ \\
\hline \multicolumn{2}{|l|}{ Smoking status } \\
\hline Never smoked & $45.4 \%$ \\
\hline Ever-smoker (currently nonsmoker) & $31.4 \%$ \\
\hline Current-smoker & $23.1 \%$ \\
\hline \multicolumn{2}{|c|}{ History of CVD (stroke, MI \& congestive heart failure) } \\
\hline No & $86.9 \%$ \\
\hline Yes & $13.1 \%$ \\
\hline \multicolumn{2}{|l|}{ Hypertriglyceridemia } \\
\hline$<150 \mathrm{mg} / \mathrm{dL}$ & $59.3 \%$ \\
\hline$\geq 150 \mathrm{mg} / \mathrm{dL}$ & $40.7 \%$ \\
\hline \multicolumn{2}{|c|}{ Decreased HDL cholesterol $(\mathrm{men} \leq 40 \mathrm{mg} / \mathrm{dL} /$ women $\leq 50 \mathrm{mg} / \mathrm{dL})$} \\
\hline No & $62.0 \%$ \\
\hline Yes & $38.0 \%$ \\
\hline \multicolumn{2}{|l|}{ Blood pressure $(\geq 130 / 85 \mathrm{mmHg})$} \\
\hline$<110 \mathrm{mmHg}$ systolic \& $85 \mathrm{mmHg}$ diastolic & $36.8 \%$ \\
\hline$>130 \mathrm{mmHg}$ systolic or $>85 \mathrm{mmHg}$ diastolic & $63.2 \%$ \\
\hline \multicolumn{2}{|c|}{ Diabetes (FBS, medications for DM \& physician diagnosis) } \\
\hline$<110 \mathrm{mg} / \mathrm{dL}$ & $74.9 \%$ \\
\hline$>110$ & $25.1 \%$ \\
\hline \multicolumn{2}{|c|}{ Central obesity (waist circumference: men $\geq 40$ inches/women $\geq 35$ inches) } \\
\hline No & $49.9 \%$ \\
\hline Yes & $50.4 \%$ \\
\hline \multicolumn{2}{|l|}{ Proinflammatory state $(\mathrm{CRP} \geq 3 \mathrm{mg} / \mathrm{dL})$} \\
\hline No & $73.0 \%$ \\
\hline Yes & $27.0 \%$ \\
\hline \multicolumn{2}{|l|}{ Prothrombotic state (fibrinogen $\geq 350 \mathrm{mg} / \mathrm{dL}$ ) } \\
\hline No & $71.7 \%$ \\
\hline Yes & $28.3 \%$ \\
\hline \multicolumn{2}{|c|}{ Metabolic syndrome (meet at criteria for 3 or ATP III criteria) } \\
\hline No & $77.9 \%$ \\
\hline Yes & $22.1 \%$ \\
\hline \multicolumn{2}{|c|}{ Renal dysfunction (eGFR in $\mathrm{mL} / \mathrm{min} / 1.73 \mathrm{~m}^{2}$ and proteinuria) } \\
\hline $0-59$ & $9.5 \%$ \\
\hline $60-89$ or eGFR $\geq 90$ with proteinuria & $43.9 \%$ \\
\hline$\geq 90$ with no proteinuria & $46.6 \%$ \\
\hline
\end{tabular}


Table 1: Continued.

\begin{tabular}{lc}
\hline Variables & $\%$ \\
\hline Renal dysfunction \& metabolic syndrome & \\
No metabolic syndrome and no renal dysfunction & $31.9 \%$ \\
No metabolic syndrome and early renal dysfunction & $24.4 \%$ \\
No metabolic syndrome and late renal dysfunction & $3.6 \%$ \\
Metabolic syndrome and no renal dysfunction & $14.7 \%$ \\
Metabolic syndrome and early renal dysfunction & $19.4 \%$ \\
Metabolic syndrome and late renal dysfunction & $6.0 \%$ \\
CVD specific mortality & \\
No & $88.2 \%$ \\
Yes & $11.8 \%$ \\
Interview/exam to mortality follow-up period in months (mean \pm std) & $96.5[ \pm 33.0]$ \\
\hline Sample excludes individuals aged $<35$ years, pregnant, or have no mortality assessment.
\end{tabular}

TABle 2: Distribution of Independent Variables and Cardiovascular Disease Mortality $(n=13115)$.

\begin{tabular}{|c|c|c|}
\hline Independent variables & $\begin{array}{c}\text { No CVD mortality } \\
\text { frequency }(\%)\end{array}$ & $\begin{array}{l}\text { CVD mortality } \\
\text { frequency }(\%)\end{array}$ \\
\hline Percentage of population & $88.2 \%$ & 11.8 \\
\hline \multicolumn{3}{|l|}{ Race } \\
\hline White & $84.5 \%$ & $15.5 \%$ \\
\hline African american & $90.7 \%$ & $9.3 \%$ \\
\hline Hispanic \& other & $92.9 \%$ & 7.1 \\
\hline \multicolumn{3}{|l|}{ Gender } \\
\hline Male & $87.1 \%$ & $12.9 \%$ \\
\hline Female & $89.1 \%$ & 10.9 \\
\hline \multicolumn{3}{|l|}{ Age (years) } \\
\hline$<64$ & $97.2 \%$ & $2.8 \%$ \\
\hline$\geq 65$ & $74.7 \%$ & 25.3 \\
\hline \multicolumn{3}{|l|}{ Poverty/income ratio } \\
\hline$<1$ & $84.9 \%$ & $15.1 \%$ \\
\hline$\geq 1$ & $90.0 \%$ & 10.0 \\
\hline \multicolumn{3}{|l|}{ Smoking status } \\
\hline Never smoked & $88.0 \%$ & $12.0 \%$ \\
\hline Ever-smoker (currently nonsmoker) & $85.6 \%$ & $14.4 \%$ \\
\hline Current smoker & $92.0 \%$ & 8.0 \\
\hline \multicolumn{3}{|l|}{ History of CVD (stroke, MI \& congestive heart failure) } \\
\hline No & $91.3 \%$ & $8.7 \%$ \\
\hline Yes & $67.0 \%$ & 33.0 \\
\hline \multicolumn{3}{|l|}{ Metabolic syndrome (meet at criteria for 3 or ATP III criteria) } \\
\hline No & $88.2 \%$ & $11.8 \%$ \\
\hline Yes & $88.2 \%$ & 11.8 \\
\hline \multicolumn{3}{|c|}{ Renal dysfunction (eGFR in $\mathrm{mL} / \mathrm{min} / 1.73 \mathrm{~m}^{2}$ and proteinuria) } \\
\hline $0-59$ & $95.3 \%$ & $33.7 \%$ \\
\hline $60-89$ or eGFR $\geq 90$ with proteinuria & $89.8 \%$ & $11.7 \%$ \\
\hline$\geq 90$ with no proteinuria & $61.9 \%$ & 4.5 \\
\hline \multicolumn{3}{|l|}{ Renal dysfunction \& metabolic syndrome } \\
\hline No metabolic syndrome and no renal dysfunction & $96.3 \%$ & $3.7 \%$ \\
\hline No metabolic syndrome and early renal dysfunction & $89.8 \%$ & $10.2 \%$ \\
\hline No metabolic syndrome and late renal dysfunction & $61.9 \%$ & $38.1 \%$ \\
\hline Metabolic syndrome and no renal dysfunction & $93.9 \%$ & $6.1 \%$ \\
\hline Metabolic syndrome and early renal dysfunction & $86.4 \%$ & $13.6 \%$ \\
\hline Metabolic syndrome and late renal dysfunction & $69.0 \%$ & $31.0 \%$ \\
\hline
\end{tabular}


Table 3: Univariate and Multivariable Cox Regression Analysis Cardiovascular Disease Mortality versus Independent Variables $(n=13115)$.

\begin{tabular}{|c|c|c|c|c|c|c|}
\hline & \multicolumn{3}{|c|}{ Univariate analysis } & \multicolumn{3}{|c|}{ Multivariable analysis } \\
\hline & OR & 95.0\% C.I. & Sig. & OR & 95.0\% C.I. & Sig. \\
\hline \multicolumn{7}{|l|}{ Race } \\
\hline White (ref) & 1.00 & - & & 1.00 & - & \\
\hline African american & 0.57 & $0.50-0.65$ & $<.001$ & 0.83 & $0.71-0.98$ & .02 \\
\hline Hispanic \& other & 0.42 & $0.36-0.48$ & $<.001$ & 0.69 & $0.59-0.82$ & $<.001$ \\
\hline \multicolumn{7}{|l|}{ Gender (ref) } \\
\hline Female & 1.00 & - & & 1.00 & - & \\
\hline Male & 1.21 & $1.09-1.33$ & $<.001$ & 1.40 & $1.23-1.59$ & $<.001$ \\
\hline \multicolumn{7}{|l|}{ Age (years) } \\
\hline$<64$ (ref) & 1.00 & - & & 1.00 & - & \\
\hline$\geq 65$ & 3.42 & $3.20-3.70$ & $<.001$ & 2.62 & $2.40-2.85$ & $<.001$ \\
\hline \multicolumn{7}{|l|}{ Poverty/income ratio } \\
\hline$<1$ (ref) & 1.00 & - & & 1.00 & - & \\
\hline$>1$ & 0.63 & $0.57-0.70$ & $<.001$ & 0.73 & $0.64-0.83$ & $<.001$ \\
\hline \multicolumn{7}{|l|}{ Smoking status } \\
\hline Never smoked (ref) & 1.00 & - & & 1.00 & - & \\
\hline Ever-smoker (currently nonsmoker) & 1.23 & $1.10-1.37$ & $<.001$ & 0.97 & $0.85-1.11$ & $\mathrm{~N} / \mathrm{S}$ \\
\hline Current-smoker & 0.64 & $0.55-0.74$ & $<.001$ & 1.07 & $0.89-1.28$ & $\mathrm{~N} / \mathrm{S}$ \\
\hline \multicolumn{7}{|l|}{ History of CVD (stroke, MI \& congestive heart failure) } \\
\hline No (ref) & 1.00 & - & & 1.00 & - & \\
\hline Yes & 5.10 & $4.60-5.66$ & $<.001$ & 2.40 & $2.11-2.72$ & $<.001$ \\
\hline \multicolumn{7}{|l|}{ Renal dysfunction \& metabolic syndrome } \\
\hline No metabolic syndrome and no renal dysfunction (ref) & 1.00 & - & & 1.00 & - & \\
\hline No metabolic syndrome and early renal dysfunction & 3.02 & $2.45-3.72$ & $<.001$ & 1.69 & $1.37-2.10$ & $<.001$ \\
\hline No metabolic syndrome and late renal dysfunction & 15.39 & $12.16-19.48$ & $<.001$ & 3.92 & $3.06-5.03$ & $<.001$ \\
\hline Metabolic syndrome and no renal dysfunction & 1.71 & $1.31-2.22$ & - & 1.22 & $0.94-1.60$ & - \\
\hline Metabolic syndrome and early renal dysfunction & 4.14 & $3.36-5.09$ & $<.001$ & 1.80 & $1.45-2.23$ & $<.001$ \\
\hline Metabolic syndrome and late renal dysfunction & 12.81 & $10.27-16.00$ & $<.001$ & 3.23 & $2.56-3.70$ & $<.001$ \\
\hline
\end{tabular}

TABle 4: Area under the Curve (AUC) for CVD Mortality using unadjusted metabolic syndrome measure compared with cocustered metabolic syndrome and early stage renal disease.

\begin{tabular}{lcccc}
\hline & Area under the ROC & Accuracy & Cohen's Kappa & Mortality cases/total \\
\hline Metabolic syndrome & 0.66 & $67.6 \%$ & 0.21 & $1551 / 13115$ \\
Metabolic syndrome and early renal dysfunction & 0.74 & $72.0 \%$ & 0.38 & $418 / 5604$ \\
\hline
\end{tabular}

Using the Cox proportional hazard model in multiple survival analysis regression tests and controlling for the influence of time to mortality assessment from baseline we explored the Univariate relationship between the predictor variables and CVD mortality (including both censored and event categories). The time to event was considered the time from the baseline laboratory measures and survey measurement to the time of mortality assessment or death of participants. A final multivariable survival analysis model was then created using all the significant predictors of CVD mortality in the univariate models to examine the influence of MetS and CKD on CVD mortality. Tests were conducted to rule out collinearity prior to running the final multivariable regression analysis model including all the covariates noted above. All data analyses were conducted using SAS (version 8.0; SAS Institute Inc, Cary, NC) and SPSS (version 15.0). Statistical hypotheses were tested using $P<.05$ as the level of statistical significance. Finally we also utilized the Bayesian analysis technique using the Waikato Environment for Knowledge Analysis software (Weka 3.0) to test the predictive accuracy of a model including a cocustered MetS and early CKD variable when compared to a model including separate MetS and early CKD measures while adjusting for other predictors of CVD mortality identified in the Univariate analysis.

\section{Results}

5.1. Sample Characteristics. The sociodemographic and clinical characteristics of the study sample are presented in 


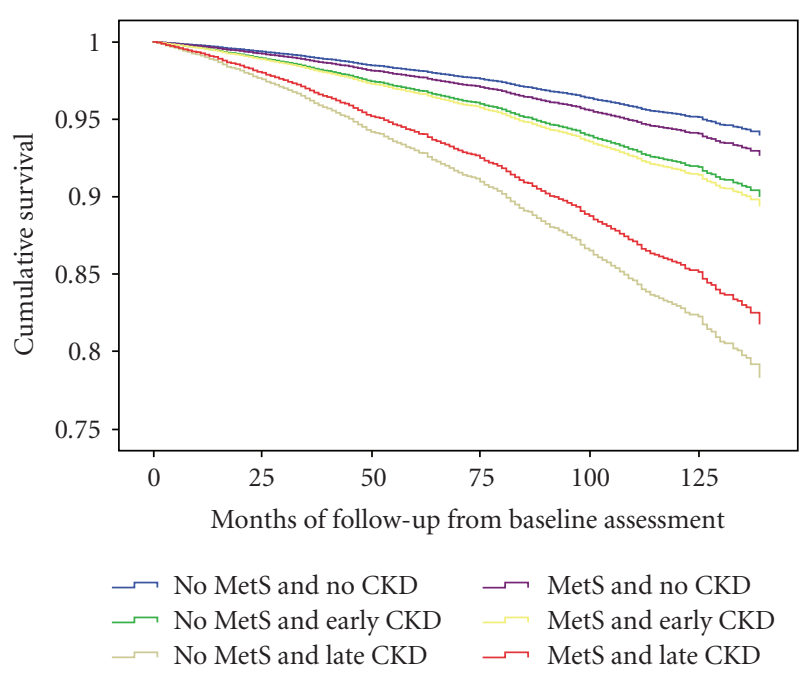

FIGURE 1: Survival function for CVD mortality versus cocustered metabolic syndrome and renal dysfunction. MetS stands for metabolic syndrome and CKD stands for chronic kidney disease.

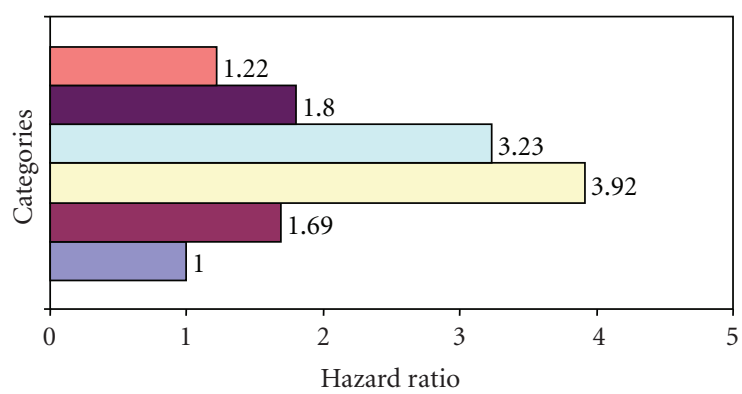

\footnotetext{
$\square$ Metabolic syndrome and no renal dysfunction

- Metabolic syndrome and early renal dysfunction

$\square$ Metabolic syndrome and late renal dysfunction

$\square$ No metabolic syndrome and late renal dysfunction

- No metabolic syndrome and early renal dysfunction

$\square$ No metabolic syndrome and no renal dysfunction (reference)
}

Figure 2: Bar chart: adjusted hazard ratios for cvd mortality versus categories of cocustered metabolic syndrome and renal dysfunction. OR for metabolic syndrome and no renal dysfunction not significant at $P<.05$.

Table 1 . Among the sample about 53\% were female and $40 \%$ were aged 65 years or older. About $22 \%$ met at least 3 criteria for MetS. About $9.5 \%$ of the sample had eGFR levels below $60 \mathrm{~mL} / \mathrm{min} / 1.73 \mathrm{~m}^{2}$ and $43.9 \%$ had eGFR between 60 and $89 \mathrm{~mL} / \mathrm{min} / 1.73 \mathrm{~m}^{2}$ or greater than 90 with some evidence of proteinuria. The mean mortality follow-up period was about 97 months and CVD specific mortality among the sample was about $11.8 \%$.

5.2. Distribution of CVD Mortality. The distribution of CVD specific mortality in the sample is presented in Table 2. Higher mortality rates were observed in individuals who were male $(12.9 \%)$, aged greater than 65 years $(25.3 \%)$, lived below the $100 \%$ federal poverty line $(15.1 \%)$, had a history of CVD (33.0\%), had eGFR below $60 \mathrm{~mL} / \mathrm{min} / 1.73 \mathrm{~m}^{2}(33.7 \%)$ or had late stage renal disease without cooccurring MetS (38.1\%) closely followed by individuals with both late stage renal disease with cooccurring MetS (31.0\%).

5.3. Unadjusted Relationship: Cocustered CKD and MetS versus CVD Mortality. Univariate analysis using Cox proportional hazard analysis demonstrated that individuals aged $\geq 65$ years or older, male, who had a history of CVD, were white and lived below the $100 \%$ federal poverty income line were more likely to had significantly greater hazard of mortality (Table 3 ). Using the cocustered CKD and MetS variables categories, the results demonstrated that in increasing order, early CKD without MetS $(\mathrm{HR}=3.02, \mathrm{CI}$ = 2.45-3.72), MetS and early CKD $(\mathrm{HR}=4.14, \mathrm{CI}=3.36-$ 5.09), MetS and late CKD $(\mathrm{HR}=12.81, \mathrm{CI}=10.27-16.00)$, and finally late $\mathrm{CKD}$ without $\mathrm{MetS}(\mathrm{HR}=15.39, \mathrm{CI}=12.16-$ 19.48) all had a statistically significant higher mortality hazard when compared to no MetS or CKD. Individuals with MetS and no CKD did not demonstrate any statistically significant difference in hazard for CVD mortality when compared with individuals with no MetS or CKD.

5.4. Adjusted Relationship: Cocustered CKD and MetS versus CVD Mortality. After adjusting for other potential predictors of mortality a Cox proportional hazard model was developed to explore the relationship between cocustered CKD and MetS with CVD mortality. All measures reported previously in the Univariate analysis model as being significantly associated with CVD mortality remained the same (Table 3 ). Using the cocustered CKD and MetS variables categories, the results demonstrated that in the same increasing order as observed in the Univariate analysis, early CKD without MetS $(\mathrm{HR}=1.69, \mathrm{CI}=1.37-2.10)$, MetS and early CKD $(\mathrm{HR}=1.80, \mathrm{CI}=1.45-2.23), \mathrm{MetS}$ and late CKD $(\mathrm{HR}$ $=3.23$, CI $=2.56-3.70)$, and finally late CKD without MetS $(\mathrm{HR}=3.92, \mathrm{CI}=3.06-5.03)$ all had a statistically significant higher mortality hazard when compared to no MetS or CKD. Individuals with MetS and no CKD did not demonstrate any statistically significant difference in hazard for CVD mortality when compared with individuals with no MetS or CKD. Figure 1 demonstrates the adjusted relative hazard for CVD mortality among the categories of cocustered CKD and MetS variable. Figure 2 presents a bar chart displaying the adjusted relative hazard ratios for CVD mortality among the categories of cocustered CKD and MetS variable.

5.5. Predictive Accuracy of Models Cocustering Early CKD and MetS versus MetS Alone for CVD Mortality. The results of the Bayesian analysis as shown in Table 4 demonstrated that for CVD mortality a model with cocustering of early CKD and MetS demonstrated higher predictive accuracy $(72.0 \%$ versus $67.6 \%$ ), area under the ROC (0.74 versus 0.66), and Cohen's kappa ( 0.38 versus 0.21$)$ than that with MetS alone. 


\section{Discussion}

The poor predictive value of the diagnosis of MetS for CVD mortality has cast serious doubt on the existence of MetS as a clinical entity distinct from its diagnostic components. However, the clustering of metabolic abnormalities that led to the description of the syndrome is still apparent in clinical practice. This clustering of metabolic abnormalities more often than would be predicted by chance alone was the basis for the description of the syndrome and the suggestion of a common etiology for its components. The initial association of the syndrome with glucose intolerance and hyperinsulinemia led to the suggestion of Insulin resistance as the probable common pathophysiological basis for the syndrome [20-22]. However, subsequent conflicting series of studies led the National Cholesterol Education Program (NCEP) Adult Treatment Panel (ATP) III to conclude that the relationship between insulin resistance and MetS is not well established [3].

The emerging role of vitamin $\mathrm{D}$ as a modulator of both insulin resistance and the renin-angiotensin system [23] and the recent implication of the renin-angiotensin system in local pancreatic islet structure and function suggest a broader base for a probable common etiology for MetS than previously anticipated. The traditional association of CKD with several components of MetS may have led to the exclusion of CKD as a component of MetS and misled the search effort for a common pathophysiological basis for the components of the syndrome. It is in the light of this emerging body of evidence that we evaluate the effect of including early CKD in the diagnostic criteria for MetS on its predictive value for CVD mortality using a nationally representative sample.

The preponderance of participants with early CKD in the analysis sample makes it suitable for the isolation of the influence of early CKD on the predictive value of MetS for CVD mortality. The association of CKD with CVD mortality in this study is consistent with the existing body of evidence and highlights the significance of CKD as an independent risk factor for CVD mortality. Even in the early stages CKD carries a significant risk for CVD mortality (OR 1.69; CI 1.37-2.10) (Table 3). In the absence of early $\mathrm{CKD}$, MetS carries no significant risk for mortality in this study. However, early CKD becomes more hazardous with a hazard ratio of 1.8 versus 1.69 for CVD mortality in the presence of MetS (Figure 2). The greater hazard of early CKD in the presence of MetS is associated with a slight but similar reduction in survival among the affected participants (Figure 1). The apparent lack of a significant association between MetS and CVD mortality is consistent with the results of several previous studies but the increase in the hazard ratio for CVD mortality associated with early CKD in the presence of MetS gives credence to a potential renal contribution to the pathogenesis and perhaps mortality of MetS.

The primary purpose of this study was to explore the implication of including indices of early CKD in the diagnostic criteria of MetS for the predictive value of the syndrome for CVD mortality. The results of this study suggest a broader base for a common etiology for MetS and support the finding of a potential renal contribution to the etiology of the syndrome. The results of this study represent an analysis of a nationally representative sample of 13,115 participants with a mean mortality follow-up period of about 97 months and CVD specific mortality of $11.8 \%$.

However, the mortality follow-up data employed in this study relied on a probabilistic match between NHANES III and National Death Index (National Center for Health Statistics (NCHS) 2006) death certificate records available and inaccurate matches for CVD specific mortality may potentially confound the study findings, particularly since a few studies suggest that appropriately identifying CVDspecific mortality may inadvertently result in misclassification of cause specific mortality [24]. Also given the cross sectional nature of risk measures utilized in our study the impact of other confounding events post assessment may impact our finding and influence the attribution of CVD mortality to our study risk measures.

Overall the study findings that early CKD may cocuster with MetS to result in an increased mortality burden should inform more studies to explore the temporal relationship between the pathogenesis of CKD and MetS.

\section{References}

[1] A. M. Minino, R. N. Anderson, L. A. Fingerhut, M. A. Boudreault, and M. Warner, "Deaths: injuries, 2002," National Vital Statistics Reports, vol. 54, no. 10, pp. 1-124, 2006.

[2] J. B. Meigs and R. P. Tracy, "Invited commentary: insulin resistance syndrome? Syndrome X? Multiple metabolic syndrome? A syndrome at all? Factor analysis reveals patterns in the fabric of correlated metabolic risk factors," American Journal of Epidemiology, vol. 152, no. 10, pp. 908-911, 2000.

[3] J. I. Cleeman, "Executive summary of the third report of the National Cholesterol Education Program (NCEP) expert panel on detection, evaluation, and treatment of high blood cholesterol in adults (adult treatment panel III)," Journal of the American Medical Association, vol. 285, no. 19, pp. 2486-2497, 2001.

[4] J. Coresh, B. C. Astor, T. Greene, G. Eknoyan, and A. S. Levey, "Prevalence of chronic kidney disease and decreased kidney function in the adult US population: third National Health and Nutrition Examination Survey," American Journal of Kidney Diseases, vol. 41, no. 1, pp. 1-12, 2003.

[5] M. J. Klag, P. K. Whelton, B. L. Randall, et al., "Blood pressure and end-stage renal disease in men," The New England Journal of Medicine, vol. 334, no. 1, pp. 13-18, 1996.

[6] S.-J. Pinto-Sietsma, G. Navis, W. M. T. Janssen, D. de Zeeuw, R. O. B. Gans, and P. E. de Jong, "A central body fat distribution is related to renal function impairment, even in lean subjects," American Journal of Kidney Diseases, vol. 41, no. 4, pp. 733741, 2003.

[7] S. Beddhu, P. L. Kimmel, N. Ramkumar, and A. K. Cheung, "Associations of metabolic syndrome with inflammation in CKD: results from the third National Health and Nutrition Examination Survey (NHANES III)," American Journal of Kidney Diseases, vol. 46, no. 4, pp. 577-586, 2005.

[8] E. D. Crook, A. Thallapureddy, S. Migdal, et al., "Lipid abnormalities and renal disease: is dyslipidemia a predictor of 
progression of renal disease?" American Journal of the Medical Sciences, vol. 325, no. 6, pp. 340-348, 2003.

[9] P. S. Leung and M. C. Chappell, "A local pancreatic reninangiotensin system: endocrine and exocrine roles," International Journal of Biochemistry and Cell Biology, vol. 35, no. 6, pp. 838-846, 2003.

[10] T. Lau, P.-O. Carlsson, and P. S. Leung, "Evidence for a local angiotensin-generating system and dose-dependent inhibition of glucose-stimulated insulin release by angiotensin II in isolated pancreatic islets," Diabetologia, vol. 47, no. 2, pp. 240 248, 2004.

[11] S. C. Smith Jr., L. T. Clark, R. S. Cooper, et al., "Discovering the full spectrum of cardiovascular disease: Minority Health Summit 2003: report of the Obesity, Metabolic Syndrome, and Hypertension Writing Group," Circulation, vol. 111, no. 10, pp. e134-e139, 2005.

[12] E. S. Ford, "Risks for all-cause mortality, cardiovascular disease, and diabetes associated with the metabolic syndrome: a summary of the evidence," Diabetes Care, vol. 28, no. 7, pp. 1769-1778, 2005.

[13] R. Kahn, J. Buse, E. Ferrannini, and M. Stern, "The metabolic syndrome: time for a critical appraisal: joint statement from the american diabetes association and the european association for the study of diabetes: response to Citrome et al., Giugliano and Esposito, Cheta, and Psaty et al," Diabetes Care, vol. 29, no. 1, pp. 177-178, 2006.

[14] A. S. Levey, J. Coresh, E. Balk, et al., "National Kidney Foundation practice guidelines for chronic kidney disease: evaluation, classification, and stratification," Annals of Internal Medicine, vol. 139, no. 2, pp. 137-147, 2003.

[15] National Center for Health Statistics, "Plan and operation of the Third National Health and Examination Survey, 19881994," Tech. Rep. (DHHS publication no. (PHS) 94-1308) (GPO no. 017-022-01260-0), National Center for Health Statistics, Hyattsville, Md, USA, 1994.

[16] National Center for Health Statistics, "Analytic and reporting guidelines: the Third National Health and Nutrition Examination Survey, NHANES III (1988-1994)," Tech. Rep., National Center for Health Statistics, Hyattsville, Md, USA, 1996.

[17] Centers for Disease Control and Prevention and NCHS Research Data Center (RDC), "NHANES III Linked Mortality File," 2007.

[18] S. M. Grundy, D. Becker, L. T. Clark, et al., "Detection, evaluation, and treatment of high blood cholesterol in adults (Adult Treatment Panel III)," Circulation, vol. 106, no. 25, pp. 3143-3421, 2002.

[19] A. S. Levey, J. Coresh, K. Bolton, et al., "K/DOQI clinical practice guidelines for chronic kidney disease: evaluation, classification, and stratification," American Journal of Kidney Diseases, vol. 39, no. 2, supplement 1, pp. S7-S10, 2002.

[20] J. W. Kolaczynski and J. F. Caro, "Insulin resistance: site of the primary defect or how the current and the emerging therapies work," Journal of Basic and Clinical Physiology and Pharmacology, vol. 9, no. 2-4, pp. 281-294, 1998.

[21] P. Zimmet, E. J. Boyko, G. R. Collier, and M. De Courten, "Etiology of the metabolic syndrome: potential role of insulin resistance, leptin resistance, and other players," Annals of the New York Academy of Sciences, vol. 892, pp. 25-44, 1999.

[22] S. M. Haffner, "Epidemiology of insulin resistance and its relation to coronary artery disease," American Journal of Cardiology, vol. 84, no. 1A, pp. 11J-14J, 1999.

[23] K. C. Chiu, A. Chu, V. L. W. Go, and M. F. Saad, "Hypovitaminosis $\mathrm{D}$ is associated with insulin resistance and $\beta$ cell dysfunction," American Journal of Clinical Nutrition, vol. 79, no. 5, pp. 820-825, 2004.

[24] J. Messite and S. D. Stellman, "Accuracy of death certificate completion: the need for formalized physician training," Journal of the American Medical Association, vol. 275, no. 10, pp. 794-796, 1996. 


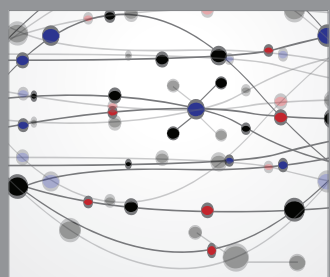

The Scientific World Journal
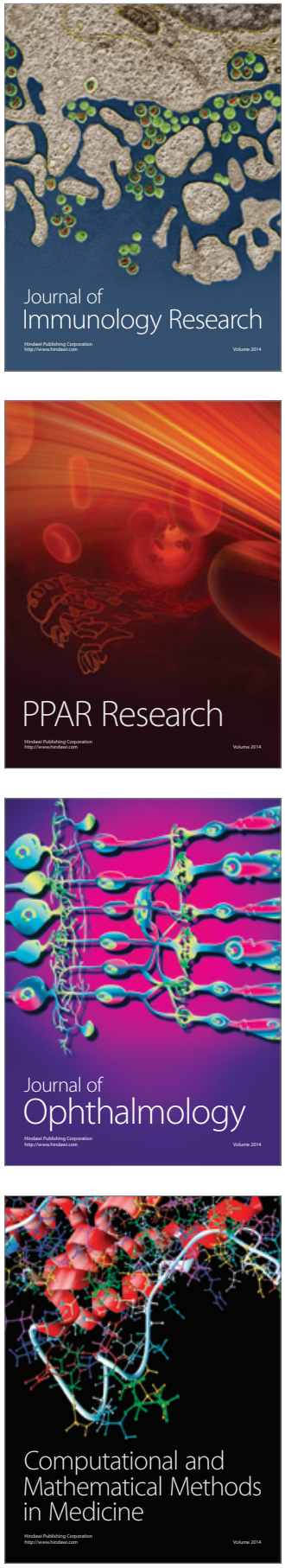

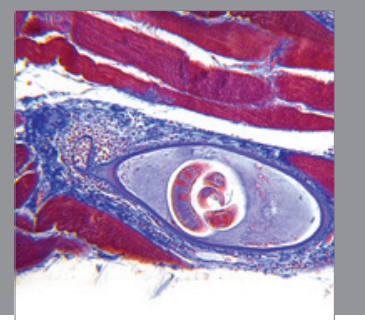

Gastroenterology

Research and Practice
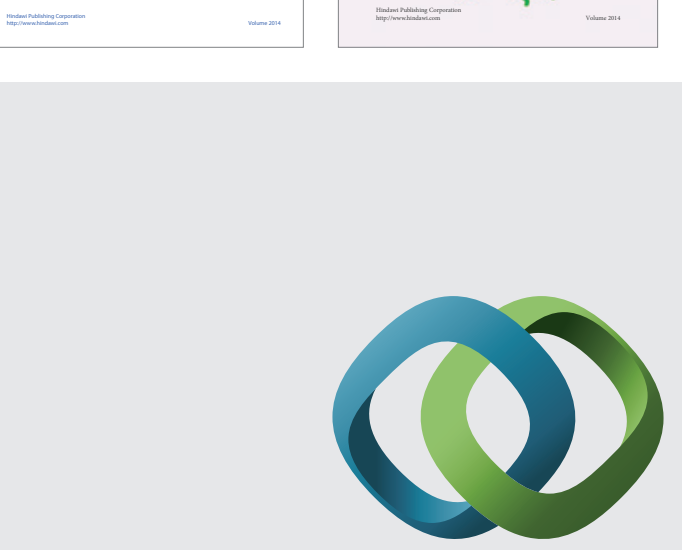

\section{Hindawi}

Submit your manuscripts at

http://www.hindawi.com
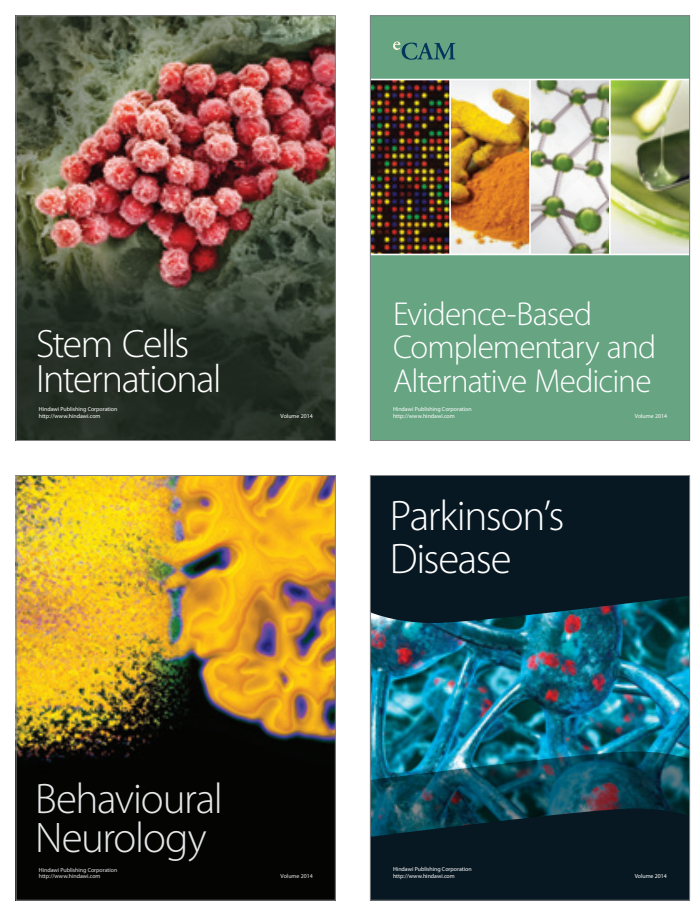

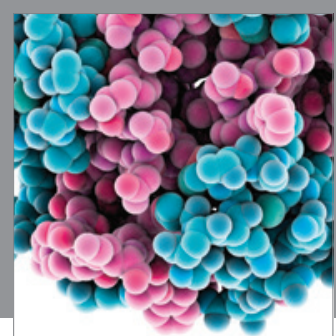

Journal of
Diabetes Research

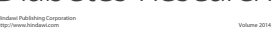

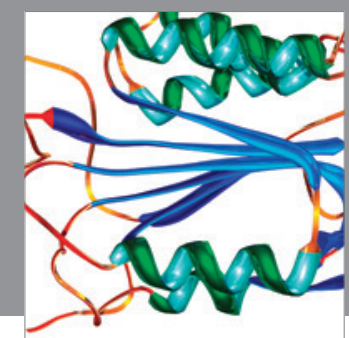

Disease Markers
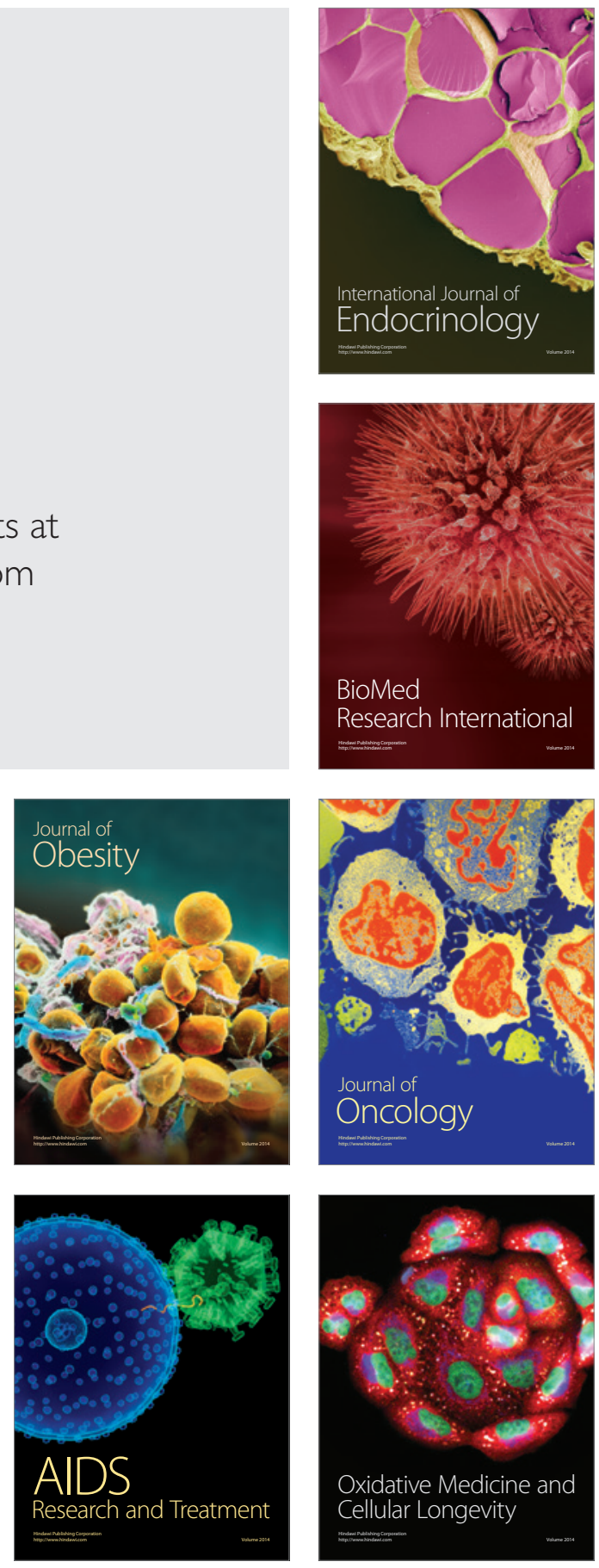